\title{
Anastomotic leaks and cancer recurrence: Associations versus causality
}

\author{
Benjamin D. Kozower, MD, MPH
}

See related article on pages $42-8$.

Kofoed and colleagues ${ }^{1}$ continue their outstanding work in this edition of the Journal, studying outcomes after resection of esophageal and gastroesophageal junction cancers. This Danish study population includes 4 certified programs in Denmark that combined their data from 2003 through 2011. During the 9-year study period, 1296 resections were performed with curative intent. These authors have previously reported that anastomotic leaks have a negative association with long-term survival. In the current article, Kofoed and colleagues ${ }^{1}$ concluded that intrathoracic anastomotic leakage increased the risk of cancer recurrence.

Resection of these cancers has been regionalized in Denmark, and the 4 centers have outstanding results, comparable with those reported from specialized general thoracic surgeons in the United States. ${ }^{2}$ Importantly, however, these Danish centers also have long-term data to study disease recurrence and survival. To arrive at their conclusion that anastomotic leaks increased the risk of cancer recurrence and death, Kofoed and colleagues ${ }^{1}$ used 7 variables in Cox proportional hazards models but did not include medical comorbidities. This is an important issue, because comorbidity and cancer stage are 2 of the strongest predictors of survival. ${ }^{3}$ Furthermore, a comorbidity such as diabetes, along with the medications used to treat the condition, may also be associated with cancer recurrence.

This article raises an interesting question and explores the association between anastomotic leak and cancer recurrence. Factors that may contribute to this result include that patients in the anastomotic group were more likely to have a higher $\mathrm{T}$ stage and that they received less adjuvant therapy. Although these factors were included in the regression, the proportion of patients completing chemotherapy was significantly lower in the leak cohort. Another potential factor contributing to this association may be a higher association

\footnotetext{
From the Department of Surgery, University of Virginia, Charlottesville, Va; and the Department of Public Health Sciences, University of Virginia, Charlottesville, Va. Disclosures: Author has nothing to disclose with regard to commercial support. Received for publication April 29, 2015; accepted for publication May 1, 2015. Address for reprints: Benjamin D. Kozower, MD, MPH, Departments of Surgery and Public Health Sciences, University of Virginia, PO Box 800679, Charlottesville, VA 22908-0679 (E-mail: bdk8g@virginia.edu).

J Thorac Cardiovasc Surg 2015; 150:49

$0022-5223 / \$ 36.00$

Copyright (c) 2015 by The American Association for Thoracic Surgery

http://dx.doi.org/10.1016/j.jtcvs.2015.05.005
}

with blood transfusions in the perioperative period; however, those data were not available in their database. Furthermore, there is a strong potential bias that needs to be understood by readers of the article. In this retrospective study, patients with an anastomotic leak may have been more likely to be followed up by a medical provider and to have surveillance imaging.

The Methods section states that surveillance imaging was symptom based, and patients who survive an anastomotic leak are at higher risk for stricture, with dysphagia and other symptoms. These patients may therefore be more likely to undergo surveillance or symptom-based imaging to detect recurrence. Finally, patients with and without disease recurrence appeared to die at almost equal rates. This is difficult to explain and is potentially related to differences in comorbidity or other confounders between the 2 groups.

It is critical that readers appreciate the methodology and claims of this article and understand that there appears to be an association between an anastomotic leak and disease recurrence. Because of the multiple potential sources of bias that may have influenced the results, it will be interesting to see whether these results are corroborated by future studies and what the mechanisms for this association may be.

\section{References}

1. Kofoed SC, Calatayud D, Jensen LS, Helgstrand F, Achiam MP, De Heer P, et al. Intrathoracic anastomotic leakage following gastroesophageal cancer resection is associated with increased risk of recurrence. J Thorac Cardiovasc Surg. 2015;150: 42-8.

2. Wright CD, Kucharczuk JC, O'Brien SM, Grab JD, Allen MS, Society of Thoracic Surgeons General Thoracic Surgery Database. Predictors of major morbidity and mortality after esophagectomy for esophageal cancer: a Society of Thoracic Surgeons General Thoracic Surgery Database risk adjustment model. J Thorac Cardiovasc Surg. 2009; 137:587-95; discussion 596.

3. Walters DM, McMurry TL, Isbell JM, Stukenborg GJ, Kozower BD. Understanding mortality as a quality indicator after esophagectomy. Ann Thorac Surg. 2014; 98:506-11; discussion 511-2 